Review Article

\title{
Remodeling the Human Adult Stem Cell Niche for Regenerative Medicine Applications
}

\author{
Silvana Bardelli ${ }^{1}$ and Marco Moccetti ${ }^{2}$ \\ ${ }^{1}$ Swiss Institute for Regenerative Medicine, Foundation for Cardiological Research and Education, Via ai Söi 24, \\ 6807 Taverne, Switzerland \\ ${ }^{2}$ Cardiology Department, Cardiocentro Ticino Foundation, Via Tesserete 48, 6900 Lugano, Switzerland \\ Correspondence should be addressed to Silvana Bardelli; silvana.bardelli@cardiocentro.org
}

Received 21 March 2017; Accepted 17 August 2017; Published 27 September 2017

Academic Editor: Karen Liu

Copyright (c) 2017 Silvana Bardelli and Marco Moccetti. This is an open access article distributed under the Creative Commons Attribution License, which permits unrestricted use, distribution, and reproduction in any medium, provided the original work is properly cited.

\begin{abstract}
The interactions between stem cells and their surrounding microenvironment are pivotal to determine tissue homeostasis and stem cell renewal or differentiation and regeneration in vivo. Ever since they were postulated in 1978, stem cell niches have been identified and characterized in many germline and adult tissues. Comprehensive studies over the last decades helped to clarify the critical components of stem cell niches that include cellular, extracellular, biochemical, molecular, and physical regulators. This knowledge has direct impact on their inherent regenerative potential. Clinical applications demand readily available cell sources that, under controlled conditions, provide a specific therapeutic function. Thus, translational medicine aims at optimizing in vitro or in vivo the various components and complex architecture of the niche to exploit its therapeutic potential. Accordingly, the objective is to recreate the natural niche microenvironment during cell therapy process development and closely comply with the requests of regulatory authorities. In this paper, we review the most recent advances of translational medicine approaches that target the adult stem cell natural niche microenvironment for regenerative medicine applications.
\end{abstract}

\section{Introduction: Highlights for the Translation of the Adult Stem Cell Niche Concept into Therapeutic Applications}

Multipotent stem cells are critical biotherapeutics for regenerative medicine because of their innate ability to restore the structure and function of adult damaged tissues or organs. As a matter of fact, self-renewal, clonogenicity, and multipotentiality are the main common features of adult stem cells. In the transition from preclinical studies to clinical application, however, we should consider a number of hurdles in manipulating stem cells and implement clinically oriented approaches to control stem cell fate and function.

The niche is a highly dynamic microenvironment that can adapt to physiological or diseased conditions $[1,2]$. The interest in targeting the stem cell niche grows and the opportunity of its remodeling represents a potential valuable therapeutic target for regenerative medicine [3-5]. Within the endogenous niche, multipotent stem cells are thoroughly connected with their surroundings and receive constant input which directs their fate. Ex vivo, culture conditions can thus modify the characteristics of cells towards their fates and further enhance their regenerative potential. Wellcharacterized adult niches vary in size and complexity: human adult stem cells can reside as individual cells within niches distributed throughout tissues. In other cases, multiple stem cell clusters are identified, as in the bulge of hair follicles or in the forebrain subventricular zone. Temporally speaking, adult stem cells can occupy a single invariant niche throughout postnatal life, for example, in the central nervous system; on the contrary, hematopoietic stem cells constantly recirculate from one bone marrow compartment to another and further activate hematopoiesis in extramedullary niches, such as in the liver and in the spleen in stress conditions, for instance during hematopoietic malignancies $[6,7]$. These 
strategies well comply with the concept of the dynamic innate regenerative capacity of the human body.

To target the stem cell niche, it might be necessary to regulate its various components such as cell-to-cell contact, cell to extracellular matrix interactions, and mechanical and electrical stimuli in a temporally and spatially regulated manner $[8,9]$. Controlling all the niche components is an unattainable goal; however, this biological complexity translates into compelling manufacturing processes for reliable, quality-assured, and cost-effective products for stem cellbased therapies [10].

Manufacturing of cell therapy products (CTPs) for clinical application typically requires challenging steps such as the specific definition of identity, potency, and purity of each CTP. These definitions are largely therapy dependent. Towards this purpose, the US Food and Drug Administration (FDA) releases the current Good Manufacturing Practice (cGMP) guidelines and the International Conference on Harmonisation (ICH) introduces a systematic approach to process manufacturing and product management based on scientific knowledge and risk assessment [2, 11]. Overall, while developing a robust manufacturing process, it is essential to identify the critical characteristics to ensure product quality that are directly linked to its safety and efficacy. Stem cell expansion may be a critical step to determine CTP quality. Variability of stem cell identity, potency, and purity is particularly relevant to CTP manufacturing, and every attempt is made to mitigate the sources of this variability. For this very reason, the reagents used in CTP manufacturing are constantly improved. Many CTPs, formerly cultured in animal serum or feeder layers, are now cultured in chemically defined, xenofree or serum-free, cGMP conditions, with the specific purpose of reducing product variability $[12,13]$. It is a critical challenge in current clinical translation to maintain ex vivo the precise characteristics of an identified stem cell and its surrounding microenvironment [14, 15].

In the following sections, we discuss the major challenges to limit adult stem cell product variability, and we describe, to the best of our knowledge, the most recent advances for their clinical translation. In general, we highlight the fact that "Clearly, fundamental scientific and medical questions reside within the niche" [16] to develop efficacious stem cell therapy products.

\section{Mimicking the Natural Physical Microenvironment: Composition of the Extracellular Matrix for Clinical Applications}

Contact with the extracellular matrix (ECM) and with other cells represents an important mechanism by which adult stem cells sense the microenvironment and make decisions about their fate [17]. The precise design of cellular biophysical microenvironment is a promising approach with the purpose of controlling stem cell behavior [18, 19]. Furthermore, the modulation of stem cell fate in vitro through an artificial microenvironment may efficiently avoid the need for direct genetic manipulation, which is more problematic for clinical application. Employing an artificial ECM aims at recreating the in vivo threedimensional (3D) microenvironment.

Noncellular niches represent the first attempt for the development of defined physical culture conditions. The most recent advances towards therapeutic application include the development of synthetic bioinformative substrates designed at the micro- and nanoscale level [20]. Microtopography and nanotopography modulate cell behavior including adhesion, self-renewal, proliferation, and differentiation and represent emerging powerful tools. Physical constraints of their microenvironment, including microand even nanoscale geometric information, are detected by cells: rigidity, stiffness, and geometry of the substrate influence stem cell behavior [21-23]. These technologies have been adapted from the microelectronics industry and employ techniques such as surface micropatterning, chemical etching, and soft lithography to obtain organized pattern and regular geometries, microfluidics, and nanoscaleengineered three-dimensional (3D) biomimetic scaffolds for high-throughput studies. Lutolf et al. showed that the 3D topography of the substrate, in synergy with its defined matrix composition, can facilitate stem cell differentiation and alignment, if clinically needed [24, 25]. Nanoscale, micropatterned, and highly flexible membranes can be used to develop retinal pigment epithelium layers for minimally invasive implantation within the eye [26]. As of today, nanotopography is equally important as a defined culture medium formulation in the optimization of stem cell culture conditions [27-29].

The mechanisms by which topographic information of the biomimetic niche influence stem cell behavior are not completely understood; they appear to involve changes in cytoskeletal organization and structure, mainly at the level of integrins in the cellular membrane as a response to the geometry and size of the ECM. This interaction activates concomitant intracellular signaling cascades and guides stem cell behavior [30, 31]. Additionally, defined surfaces such as synthetic peptides containing the Arg-Gly-Asp (RGD) motif for cell attachment are still fairly new and represent a successful option for cell expansion [32-34].

In general, synthetic peptides and surfaces offer the advantage of being animal component free (ACF) and are potentially scalable. Matrigel, a poorly defined complex ECM isolated from the murine Engelbreth-Holm-Swarm tumor, would not be the ideal choice for clinical applications $[35,36]$. Recombinant versions of single-ECM proteins, such as fibronectin and laminin, exist and offer the opportunity of designing a whole ACF cell environment. However, at present, recombinant proteins are still cost prohibitive for largescale cell therapy product manufacturing.

Biocompatible hydrogel-based ECMs are employed for the culture of stem cells. Hydrogels are 3D macromolecule platforms obtained by the crosslinking of hydrophilic polymers. Collagen, fibrin, hyaluronic acid, alginate, dextran, chitosan, and agarose are used as components for hydrogels $[37,38]$. However, fine modulation of their mechanical properties, degradation rate, and reproducibility is a challenge. Consequently, hydrogels polymerized with synthetic (chemically defined) peptides such as polylactic-glycolic acid 
(PLGA) or polyethyleneglycol (PEG) are developed [39, 40]. Many biodegradable synthetic hydrogel-based products are approved for clinical use by the FDA and they are specifically designed for each clinical application. These defined biomimetic ECMs are effective in creating an adequate microenvironment for adult stem cells; however, it does not seem that they are sufficient to guarantee long-term maintenance of stem cells in vitro. Thus, we further analyze the additional important components of the stem cell niche to proceed to clinical application.

\section{Moving towards Standardization of Cell Therapy Products: A Chemically Defined Microenvironment}

In vitro, cultured cells are subjected to an environment whose main components are, together with the substrate, the culture medium, the atmosphere, and cell-to-cell interactions. Each of these components participate to the complex network of signaling pathways that eventually determine stem cell fate $[22,23]$. Stem cell culture is widely employed in basic research and its optimization produces expanded cells in clinically relevant numbers $[28,32]$. Culture media and their supplements provide the most fundamental nutrients to cultured cells: essential amino acids, a carbon source (typically glucose and galactose), basic salts, lipids, metal ions, a buffer system to maintain $\mathrm{pH}$, an iron carrier (e.g., transferrin), growth factors, or hormones. Media supplements provide adhesion factors and they favor protection from shear forces (e.g., through surfactants or albumin). Overall, the medium and its components mimic as much as possible the situation in vivo.

A universally optimal culture condition does not exist because stem cells are all different. Stem cell culture parameters are defined for each stem cell type and designed on their intended therapeutic use [41, 42]. Feeder layers supply growth factors, cytokines, and other extracellular matrix components such as leukemia inhibitory factor (LIF), activin, Wnt, bone morphogenetic proteins (BMPs), insulin-like growth factor (IGF), laminin, and vitronectin to maintain an undifferentiated state. These cell culture conditions are ill defined: Mallon et al. reported that feeder cells show batch-to-batch variability to maintain human embryonic stem cell (hESC) self-renewal and limited culture scale-up [43]. Negative results related to xenotransmission are also detected in long-term culture [44]. This demonstrates the unsuitability of cellular feeder layers as a culture component. Thus, studies on the development of feeder-free, possibly serum-free, and physicochemically defined culture systems are strongly encouraged.

Good Cell Culture Practice (GCCP) and Good Manufacturing Practice (GMP) represent the leading guidelines to establish standardized protocols for cell-based therapy and regenerative medicine [45]. As a matter of fact, the design of fully defined media able to maintain stemness, or alternatively to induce differentiation towards well-defined phenotypes, is a point of major interest for stem cell culture today. Chemically defined media used for the growth of
Chinese Hamster Ovary (CHO) represent an instructive lesson from the past.

The advantage of defined media, aside from the desirable ethical reduction or complete absence of fetal bovine serum (FBS), is the precise chemical composition which thus facilitates a controlled culture environment for the selective growth of cells. Defined culture conditions allow the establishment and the maintenance of phenotypically welldefined and karyotipycally stable cells.

Cell culture conditions are further optimized by the implementation of specific stem cell supplements, that is, recombinant growth factors or cytokines. The selection of the medium additives and their concentrations, especially the growth factors, is critical since it could variably affect the cultured cells. Adult stem cells require ex vivo-specific growth factors that mimic their native microenvironment.

Growth factors act as mitogens that stimulate cell proliferation and in some cases are crucial to maintain cell characteristics. The most commonly used growth factors in ACF or xenofree (XF) media for human adult stem cells include basic fibroblast growth factor, epidermal growth factor, transforming growth factor- $\beta$, vascular endothelial growth factor, and platelet-derived growth factor $[46,47]$. Most of these growth factors are available as recombinant proteins and are widely used for cell therapy applications.

The specificity of growth factors, their concentration, and synergistic effect play a crucial role in achieving an optimized, cell-specific, defined culture medium. Notably, growth factor requirements can be not only cell-type specific but also species specific: LIF supports the expansion of a mouse but not human ESCs. Secreted molecules, such as colony-stimulating factor and stem cell factor (Kit ligand), play important roles in cell survival.

Cell-to-cell interactions involving other classes of molecules are also important: interactions between Eph tyrosine kinase receptors and their Ephrin transmembrane ligands regulate adult stem cell proliferation and migration [48].

Efficient stem cell manufacturing in vitro is crucial to guarantee a long-term therapeutic effect in vivo. This critical issue increases our knowledge on the fine regulation of stem cell microenvironment and moves translational research into effective and more reproducible clinical trials.

\section{Bioreactors: 3D Mechanical Force Mimicking the Controlled Oxygen Perfusion in Stem Cell Niches}

For decades, cells are cultured under an atmospheric oxygen pressure that is much higher than the one experienced in their niches in vivo. Cell culture incubators normally preserve atmospheric partial oxygen pressure ( $\mathrm{pO} 2)$ which is around $150 \mathrm{mmHg}\left(21 \% \mathrm{O}_{2}\right)$. In vivo, physiological $\mathrm{pO} 2$ ranges between 50 and $5 \mathrm{mmHg}(7-0.7 \%)$. Thus, the term "normoxia" referred to standard cell culture systems does not refer to physiological conditions. Lowering the $\mathrm{pO} 2$ is beneficial for various adult stem cell types [49]: Wion et al. reported that bone marrow mesenchymal stem cell 
expansion was more efficient at $2 \%$ pO2 [50]. Additionally, the $\mathrm{pO} 2$ found in adult stem cell niches is variable.

The stem cell culture medium is dynamic and changes rapidly due to the release and/or consumption of numerous metabolites. For this reason, continuous perfusion of cell cultures with fresh medium through controlled bioreactors is considered a valuable option to standardize cellmanufacturing processes. Bioreactors utilize mechanical forces to influence biological processes under closely controlled conditions. They provide spatially homogeneous cell distribution; deliver physiological relevant concentrations of oxygen, carbon dioxide, and nutrients in the culture medium; and provide physical stimuli to regulate stem cell differentiation and proliferation. In bioreactors, stem cells are expanded in stirred vessels or on perfused scaffolds, and their culture $\mathrm{pH}$ and oxygen values are monitored. This controlled process is beneficial in terms of stem cell expansion and differentiation compared to conventional static culture conditions, although autocrine and paracrine loops might be disturbed [51]. The implementation of sensitive monitoring systems and control algorithms is required to increase cell product reproducibility. Various types of bioreactors exist and are employed in the manufacturing of stem cell therapy products.

\section{Reduction of Animal-Derived Components: Serum-Free Culture and Its Impact on the Niche Microenvironment}

Serum is a mixture of a large number of components, and its composition is partly uncharacterized. Slight variations in its composition influence key properties of cells because they are highly sensitive to culture conditions. Thus, serum introduces an unknown variable into the culture system, and this represents a challenge to generate consistent and qualityassured cells in clinical-scale production $[52,53]$.

In cell culture, the use of fetal bovine serum (FBS) as a medium supplement is most widespread. The major function of serum in stem cell culture media is to provide multiple elements that correspond to the in vivo condition: hormonal factors for cell growth and proliferation transport proteins that carry hormones, minerals, trace elements (e.g., transferrin), and lipids (e.g., lipoproteins). Additionally, it stabilizes $\mathrm{pH}$ with factors inhibiting proteases (such as $\alpha$-antitrypsin or $\alpha 2$-macroglobulin), supplies adhesion molecules of the extracellular matrix, and contains factors that protect against shear forces $[54,55]$.

The critical problems related to the presence of FBS in stem cell culture are batch-to-batch variability, fluctuating availability, unexpected cell characteristics, and potential cytotoxicity of uncharacterized factors [56-58]. Gstraunthaler et al. raised several ethical issues concerning the use and collection of FBS $[59,60]$. Most importantly, the immunogenicity of cells cultured in FBS has proven to be challenging for their use in therapeutic strategies.

Most regulatory agencies tolerate the use of xenogenic components in culture media in phase I clinical trials. However, later phase trials are required to employ serum-free or at least xenofree media. Mendicino et al. reported recently that
FBS is employed during manufacturing in over $80 \%$ of the investigational new drug (IND) applications for mesenchymal stem cell (MSC) products submitted to the FDA [61]. The concentration of FBS ranges from 2 to 20\%, with $10 \%$ FBS being the most common concentration. Serum consumption increases on the average of $10 \%-15 \%$ annually, which suggests that the demand for serum will soon exceed the actual availability. Safety concerns represent sound reasons to search for serum substitutes or serumfree media [62-64].

The major benefits of establishing serum-free cell culture systems are in the direction of standardization, that is, limitation of the cell therapy product variability, and elimination of a potential source of contamination $[65,66]$. Of note, serumfree media are generally more cell specific.

Adult stem cells cannot survive in the absence of serumspecific growth factors as well as other unidentified factors in the serum. In serum-free culture, a separate attachment substrate is required. Human plasma fibronectin is a common adhesion substrate used in serum-free systems [67]. Human platelet lysates (HPLs) are considered a valuable FBS alternative for adult stem cell expansion [68]. Platelet granules contain various growth factors and cytokines that can be released by freeze/thaw-mediated lysis, sonication, or chemical treatment. Due to the wound healing property of platelets in vivo, growth factors such as platelet-derived growth factor (PDGF), transforming growth factor- $\beta$ (TGF- $\beta$ ), fibroblast growth factor (FGF), insulin-like growth factor-1 (IGF-1), platelet-derived epidermal growth factor (EGF), vascular endothelial growth factor (VEGF), together with attachment factors (fibronectin and vitronectin), and protease inhibitors are exploited for their use [69]. However, hPL preparations are subjected to donor-to-donor variations.

Pooled human AB serum (HABS) is an additional alternative: it supports proliferation of human mesenchymal stromal cells (hMSCs) and maintains their characteristics throughout ex vivo expansion [70]. Furthermore, human umbilical cord blood serum (hUCBS) is a rich source of soluble growth factors. hUCBS supports the growth, proliferation, and differentiation of the resident stem cell population in the fetal blood. Cord blood defines distinct characteristics in cord bloodderived stem cells, and this supplement may constitute a unique microenvironment to support ex vivo culture of adult stem cells [71]. However, the drawbacks of hUCBS are various, likewise any other blood-derived alternative to FBS. In general, the possibility of contamination from adventitious agents, lot-to-lot variability, and limitation of collection volumes remain a challenge. Contamination issues are kept controlled by strict adherence to blood bank quality standards.

To overcome the issue of limited collection availability, recombinant forms of human serum albumin are commercially available. Recombinant human serum albumin ( $r-$ HSA) is used instead of purified human serum albumin (HSA) [72]. r-HSA is structurally identical to HSA but it is free from viral and prion contamination, and it guarantees high batch-to-batch consistency. Recombinant human albumin is more likely to be compliant with regulatory requirements and may serve as an ACF ancillary product for cell therapy and regenerative medicine applications 
[56, 61]. The major disadvantage is the price, which is several times higher for r-HSA than for purified HSA.

A few serum-free media are also commercially available. Unfortunately, the composition of commercially available proprietary serum-free media is generally unknown. Manufacturers usually do not disclose this information that is often requested by regulatory authorities in clinical settings.

The process of developing serum-free media or adapting stem cells to serum-free culture media is complex and time consuming. However, the development of these defined media should be encouraged in view of their intended clinical application. As stem cell therapy industry advances and clinical trials reach their later phases, culture process validation, scale-up, and quality assurance of critical raw material are highly requested.

Addressing this need results in significant changes to current culturing technologies for a beneficial shift towards more qualified and compelling therapies. Table 1 shows an overview of the current alternatives for clinical applications.

\section{The Cardiac Stem Cell Niche in Regenerative Medicine}

Extracellular matrix (ECM) composition is precisely regulated during normal heart development and its dysregulation results in structural and functional heart diseases.

The heart is a biomechanical organ in which the mechanical stress on cardiac cells mainly arises from the hemodynamic load. Dysregulation of either preload in diastole or afterload in systole contributes to the pathogenesis of congenital or adult heart disease. The microenvironment of stem cells in the adult myocardium includes cardiomyocytes, vasculature, interstitial cells, and extracellular matrix, each of them representing a potential target to enhance the regenerative potential of the heart after injury.

Cardiovascular diseases represent a major public health priority. Specifically, patients who suffer from myocardial infarction may encounter adverse remodeling that can ultimately lead to heart failure. Prognosis of patients affected by heart failure is very poor with 5 -year mortality close to $50 \%$. Despite the impressive progress in the clinical treatment of heart failure in recent years, heart transplantation is still required to avoid death as the result of the inexorable decline in cardiac function. Nonetheless, the morbidities associated with heart transplantation and the limited organ supply demand the development of new stem cell-based approaches for regenerative medicine [82-84].

The human heart is one of the organs which regenerates less in the body, or at least, its regenerative potential is clearly lower than the intestine, liver, bone, or skin [85]. However, some degree of cardiomyocyte renewal has to be recognized $[86,87]$. Despite the fact that proliferative rates are clearly small and quite difficult to detect, they raise the question whether such innate processes could be increased and employed therapeutically. Given these observations, the main objective of cardiac regenerative medicine is to replace damaged heart cells and, therefore, to restore the physiological structure and function of the organ [88, 89]. Various clinical trials employ adult stem cells to regenerate the heart.
The past decade highlighted the most instructive stem cellbased studies for cardiac diseases. These first-generation adult stem cell therapies for myocardial regeneration were promising in small animal models but beneficial effects in humans were far more moderate [90]. Consequently, the objective of second-generation therapeutic approaches is the enhancement of cellular properties and survival to restore the normal function of the myocardium.

Current investigation deals with combinatory approaches that employ multiple stem cell types. Preconditioning stem cells in vitro with growth factors, hypoxic treatment, or antiaging reagents enhances cellular engraftment, survival, and differentiation before administration. An example of this valuable approach involves the "cardiopoietic" guidance of multipotent adult stem cells: Behfar et al. employed a specific cardiogenic cocktail for human mesenchymal stem cells through manipulation of their culture environment [91]. The authors assessed this approach in the C-CURE trial (ClinicalTrials.gov Indentifier: NCT00810238) and in the larger CHART-1 (ClinicalTrials.gov Indentifier: NCT01768702) clinical trial to treat ischemic heart failure. So far, preliminary results indicate a positive although not statistically significant trend in the treated group.

Engineered scaffolds represent 3D myocardial tissue for adult stem cell culture; this approach includes synthetic porous scaffolds or scaffold-free cell sheets to increase cardiac contractility and output. In an effort to use physicochemically defined components, recombinant human laminin and recombinant human fibronectin in our hands (Figure 1, unpublished results) are used [92].

Complex 3D ECM, including ECM obtained from decellularized hearts, provides a superior microenvironment over single 2D ECM components with regard to cardiac stem cell structural organization and function [93-95]. Hydrogels are an effective alternative to scaffolds: they create a synthetic microenvironment for cells in vitro and are subsequently administered into the myocardium as a patch or injected into the damaged region of the heart. 3D bioprinting recently emerged as an exciting technological advancement for the construction of 3D myocardial tissue: it is now possible to print native cardiac tissue or custom-made patient-specific devices for cardiovascular diseases.

Exosomes carrying noncoding RNAs are important players for intercellular communication in the heart. MicroRNAs (miRNAs) and long noncoding RNAs (lncRNAs) act as critical regulators of cardiac development and disease: they necessitate the implementation into future efforts at mimicking the cardiac microenvironment in vitro. miR-15, miR-17, mrR-133a, miR-199a, miR-210, miR-451, and miR-499 improve myocardial structure and function after ischemia or infarction.

Future models may expand into gene therapies: the analysis of mononuclear polyploid cells naturally occurring in regenerative tissues represents a more recent approach [96].

\section{Conclusions}

Several studies performed in the last decades highlight the importance of the microenvironment in which human 
TABLE 1: A comprehensive overview of the current available alternatives to recreate the stem cell microenvironment in vitro for clinical applications.

\begin{tabular}{|c|c|c|c|}
\hline $\begin{array}{l}\text { Component of the native stem cell } \\
\text { niche microenvironment }\end{array}$ & Function in vivo & $\begin{array}{l}\text { Corresponding } \\
\text { component in vitro }\end{array}$ & Most recent alternatives \\
\hline Extracellular matrix (ECM) & $\begin{array}{l}\text { Physical adhesion; } \\
\text { Cell orientation; } \\
\text { Stem cell fate }\end{array}$ & $\begin{array}{l}\text { Scaffolds or matrices } \\
\quad(2 \mathrm{D} \text { or } 3 \mathrm{D}) \\
\text { Coating substrates }\end{array}$ & $\begin{array}{c}\text { Hydrogels }[39,40] ; \\
\text { Synthetic peptides (RGD) [73]; } \\
\text { Micro- and nanotopographic biomimetic } \\
\text { scaffolds }[20,74]\end{array}$ \\
\hline \multirow{4}{*}{ Chemical microenvironment } & $\begin{array}{l}\text { Provides fundamental nutrients } \\
\text { (salts, ions, lipids, etc.); } \\
\text { Buffering system }\end{array}$ & Cell culture medium & $\begin{array}{l}\text { Cell-type-specific chemically defined } \\
\text { (serum-free) culture medium }[75,76]\end{array}$ \\
\hline & $\begin{array}{l}\text { Adhesion factors; } \\
\text { Protection from shear forces; } \\
\text { Cell proliferation }\end{array}$ & $\begin{array}{l}\text { Fetal bovine } \\
\text { serum (FBS) }\end{array}$ & $\begin{array}{c}\text { Human platelet lysates [77]; } \\
\text { Human pooled AB serum [78]; } \\
\text { Human umbilical cord blood serum [71]; } \\
\text { Recombinant human serum albumin [72]; } \\
\text { Serum-free (or reduced FBS) } \\
\text { culture systems [79] }\end{array}$ \\
\hline & Cell proliferation & $\begin{array}{l}\text { Feeder cells; } \\
\text { Growth factors }\end{array}$ & $\begin{array}{c}\text { Feeder-free systems [44]; } \\
\text { Recombinant human growth factors [80] }\end{array}$ \\
\hline & Cell metabolism and survival & Oxygen & $\begin{array}{l}\text { Bioreactor-controlled oxygen } \\
\text { perfusion }[51,81]\end{array}$ \\
\hline
\end{tabular}

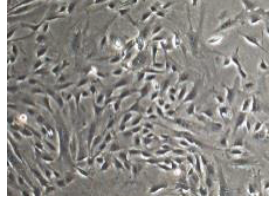

$10 \%$ FBS

(a)

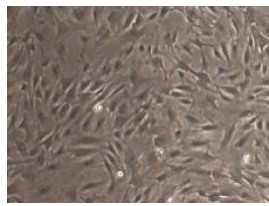

$10 \%$ FBS

(e)

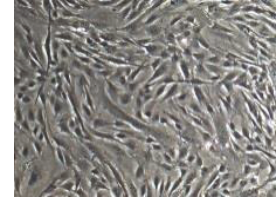

5\% FBS

(b)

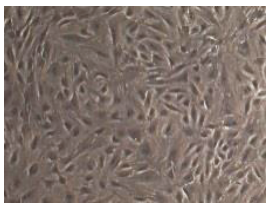

$5 \%$ FBS

(f)

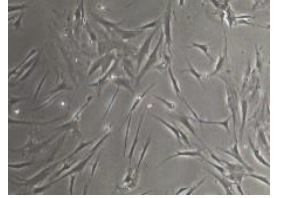

$3 \%$ FBS

(c)

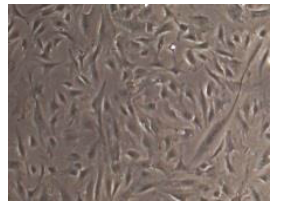

$3 \%$ FBS

(g)

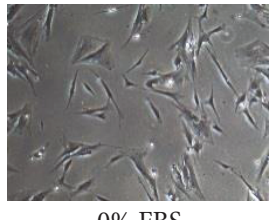

$0 \%$ FBS

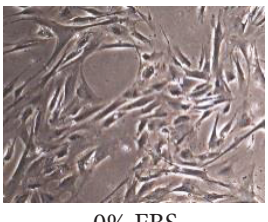

(h)

Figure 1: (a, b, c, d) Human cardiac biopsy-derived stem cells cultured in sequentially optimized serum-free culture medium on recombinant human fibronectin-coated surface. $(e, f, g, h)$ Control culture of human cardiac biopsy-derived stem cells in commercially available serum-free proprietary medium (Essential $6^{\mathrm{TM}}$, Gibco) on fibronectin-coated surface. Authors' unpublished results.

stem cells grow and maintain their peculiar characteristics. Various components of the human stem cell niche are clarified, and the objective of recreating an appropriate native microenvironment is the current objective of regenerative medicine.

Manufacturing human adult stem cells as therapeutics should preferably be performed in animal component-free or reduced animal component systems to avoid the risk of zoonoses. Ideally, the cell culture systems that are engineered for this purpose will minimize exposure to animal cells and proteins by using primarily human or recombinant human components. Furthermore, it is highly desirable to employ physicochemically defined culture media, possibly devoiding complex mixtures such as animal or human serum.

We are moving closer to producing stem cell therapy products that have very limited contact with animal products and thus are better candidates for use in regenerative therapies. Although many challenges lie ahead in the industrialization of CTP manufacturing, we find much reason for optimism. Decades of experience with industrial cell line culture processes lay the foundation of engineering CTPs such as bioreactor scale-up, analysis of cellular metabolism, medium design, optimization of expansion strategies, and process control. Meanwhile, our understanding of how cells interact with their environment is improving, and controlled systems that mimic the cellular microenvironment are generating important data sets which are increasingly focused on molecular and cellular information. In parallel, our general understanding of the molecular basis of stem cell states, including adhesion properties, metabolic needs, clonogenicity, and proliferation control, is progressing. Such findings emphasize the importance of a multidisciplinary approach 
for the development of engineered products, involving the connection of many disciplines such as cell and molecular biology, materials science, biomedical engineering, and medicine. The global perspective is the implementation of a comprehensive cell therapy product including a defined serum-free culture medium, a perfusion system, biosensors, and micro- or nanoscale-designed scaffolds mimicking as far as possible the niche microenvironment that is known to modulate stem cell function. The future lies probably in the development of 3D modular biomimetic systems assembled according to the final purpose of the stem cell culture, for example, stemness maintenance or control of cell differentiation towards clinically relevant cell phenotypes.

This massive development requires time and resources and may also involve remarkable changes to be implemented into the original manufacturing process. Additionally, full characterization of the final stem cell product after process development changes is crucial to verify comparability to the original product. It is also critical to carefully examine the quality, safety, and availability of the specific components implemented into the system to ensure that the selection meets the needs for further scale-up of the process and resulting therapeutic product.

The future of CTPs relies on the development of cost-effective technologies for cell manufacturing. Given the inherent complexity of CTPs and their production processes, appropriately designed approaches will be essential in transforming today's experimental CTPs into available therapeutics.

The advancement of the knowledge and optimization of the integral components of the human stem cell niche are instrumental in this ambitious goal.

\section{Conflicts of Interest}

The authors declare that there is no conflict of interest regarding the publication of this paper.

\section{References}

[1] G. B. Adams and D. T. Scadden, "A niche opportunity for stem cell therapeutics,” Gene Therapy, vol. 15, no. 2, pp. 96-99, 2008.

[2] G. B. Adams, R. P. Martin, I. R. Alley et al., "Therapeutic targeting of a stem cell niche," Nature Biotechnology, vol. 25, no. 2, pp. 238-243, 2007.

[3] M. L. Weiss, M. S. Rao, R. Deans, and P. Czermak, "Manufacturing cells for clinical use," Stem Cells International, vol. 2016, Article ID 1750697, 5 pages, 2016.

[4] L. Zon, "Translational research: the path for bringing discovery to patients," Cell Stem Cell, vol. 14, no. 2, pp. 146-148, 2014.

[5] A. J. Wagers, "The stem cell niche in regenerative medicine," Cell Stem Cell, vol. 10, no. 4, pp. 362-369, 2012.

[6] D. Bhattacharya, A. Czechowicz, A. G. Ooi, D. J. Rossi, D. Bryder, and I. L. Weissman IL., "Niche recycling through division-independent egress of hematopoietic stem cells," The Journal of Experimental Medicine, vol. 206, no. 12, pp. 2837-2850, 2009.
[7] S. Jaiswal, C. H. Jamieson, W. W. Pang et al., "CD47 is upregulated on circulating hematopoietic stem cells and leukemia cells to avoid phagocytosis," Cell, vol. 138, no. 2, pp. 271-285, 2009.

[8] Y. Reinwald, J. Bratt, and A. El Haj, "Pluripotent stem cells and their dynamic niche," in Chapter from the Book Pluripotent Stem Cells-from the Bench to the Clinic InTechOpen, InTech, Rijeka, 2016, http://irep.ntu.ac.uk/id/eprint/31093/.

[9] D. L. Jones and A. J. Wagers, "No place like home: anatomy and function of the stem cell niche," Nature Reviews Molecular Cell Biology, vol. 9, no. 1, pp. 11-21, 2008.

[10] A. D. Lander, J. Kimble, H. Clevers et al., "What does the concept of the stem cell niche really mean today?," BMC Biology, vol. 10, p. 19, 2012.

[11] US Food and Drug Administration, "Guidance for Industry: Q8 (R2) pharmaceutical development," 2009, http://www.fda. gov/downloads/Drugs//Guidances/ucm073507.pdf, (International Conference on Harmonization).

[12] J. Carmen, S. R. Burger, M. McCaman, and J. A. Rowley, "Developing assays to address identity, potency, purity and safety: cell characterization in cell therapy process development," Regenerative Medicine, vol. 7, no. 1, pp. 85-100, 2012.

[13] R. C. Nordberg and E. G. Loboa, "Our fat future: translating adipose stem cell therapy," Stem Cells Translational Medicine, vol. 4, no. 9, pp. 974-979, 2015.

[14] M. K. Carpenter, "Regulatory considerations for pluripotent stem cell therapies," Progress in Brain Research, vol. 230, pp. 151-163, 2017.

[15] J. Tarnowski, D. Krishna, L. Jespers et al., "Delivering advanced therapies: the big pharma approach," Gene Therapy, 2017, https://www.ncbi.nlm.nih.gov/pubmed/?term=J .+Tarnowski\%2C+D.+Krishna\%2C+L.+Jespers+2017.

[16] S. J. Morrison and A. C. Spradling, "Stem cells and niches: mechanisms that promote stem cell maintenance throughout life," Cell, vol. 132, no. 4, pp. 598-611, 2008.

[17] J. Zhang and L. Li, "Stem cell niche: microenvironment and beyond," The Journal of Biological Chemistry, vol. 283, no. 15, pp. 9499-9503, 2008.

[18] D. J. Prockop, C. A. Gregory, and J. L. Spees, “One strategy for cell and gene therapy: harnessing the power of adult stem cells to repair tissues," Proceedings of the National Academy of Sciences of the United States of America, vol. 100, Supplement 1, pp. 11917-11923, 2003.

[19] F. Guilak, D. M. Cohen, B. T. Estes, J. M. Gimble, W. Liedtke, and C. S. Chen, "Control of stem cell fate by physical interactions with the extracellular matrix," Cell Stem Cell, vol. 5, no. 1, pp. 17-26, 2009.

[20] T. Fujie, Y. Mori, S. Ito et al., "Micropatterned polymeric nanosheets for local delivery of an engineered epithelial monolayer," Advanced Materials, vol. 26, pp. 1699-1705, 2014.

[21] A. J. Engler, S. Sen, H. L. Sweeney, and D. E. Discher, "Matrix elasticity directs stem cell lineage specification," Cell, vol. 126, no. 4, pp. 677-689, 2006.

[22] S. J. Greco and P. Rameshwar, "Microenvironmental considerations in the application of human mesenchymal stem cells in regenerative therapies," Biologics: Targets and Therapy, vol. 2, no. 4, pp. 699-705, 2008.

[23] S. Eshghi and D. V. Schaffer, "Engineering microenvironments to control stem cell fate and function," in StemBook [Internet], Harvard Stem Cell Institute, Cambridge (MA), 2008.

[24] M. P. Lutolf and J. A. Hubbell, "Synthetic biomaterials as instructive extracellular microenvironments for morphogenesis 
in tissue engineering," Nature Biotechnology, vol. 23, pp. 47$55,2005$.

[25] N. Gjorevski, N. Sachs, A. Manfrin et al., "Designer matrices for intestinal stem cell and organoid culture," Nature, vol. 539, no. 7630, pp. 560-564, 2016.

[26] L. Lu, M. J. Yaszemski, and A. G. Mikos, "Retinal pigment epithelium engineering using synthetic biodegradable polymers," Biomaterials, vol. 22, no. 24, pp. 3345-3355, 2001.

[27] J. Barthes, H. Özçelik, M. Hindié, A. Ndreu-Halili, A. Hasan, and N. E. Vrana, "Cell microenvironment engineering and monitoring for tissue engineering and regenerative medicine: the recent advances," BioMed Research International, vol. 2014, Article ID 921905, 18 pages, 2014.

[28] H. Zhang, S. Dai, J. Bi, and K. K. Liu, "Biomimetic threedimensional microenvironment for controlling stem cell fate," Interface Focus, vol. 1, no. 5, pp. 792-803, 2011.

[29] M. Hosseinkhani, R. Shirazi, F. Rajaei, M. Mahmoudi, N. Mohammadi, and M. Abbasi, "Engineering of the embryonic and adult stem cell niches," Iranian Red Crescent Medical Journal, vol. 15, no. 2, pp. 83-92, 2013.

[30] J. Kshitiz, P. Park, W. Kim et al., "Control of stem cell fate and function by engineering physical microenvironments," Integrative Biology (Camb), vol. 4, no. 9, pp. 1008-1018, 2012.

[31] S. Even-Ram, V. Artym, and K. M. Yamada, "Matrix control of stem cell fate,” Cell, vol. 126, no. 4, pp. 645-647, 2006.

[32] J. H. Jordahl, L. Villa-Diaz, P. H. Krebsbach, and J. Lahann, "Engineered human stem cell microenvironments," Current Stem Cell Reports, vol. 2, pp. 73-84, 2016.

[33] R. Rakian, T. J. Block, S. M. Johnson et al., "Native extracellular matrix preserves mesenchymal stem cell "stemness" and differentiation potential under serum-free culture conditions," Stem Cell Research \& Therapy, vol. 6, p. 235, 2015.

[34] F. Gattazzo, A. Urciuolo, and P. Bonaldo, "Extracellular matrix: a dynamic microenvironment for stem cell niche," Biochimica et Biophysica Acta, vol. 1840, no. 8, pp. 2506-2519, 2014.

[35] M. Nagaoka, K. Si-Tayeb, T. Akaike, and S. A. Duncan, "Culture of human pluripotent stem cells using completely defined conditions on a recombinant E-cadherin substratum," BMC Developmental Biology, vol. 10, p. 60, 2010.

[36] N. T. Kohen, L. E. Little, and K. E. Healy, "Characterization of matrigel interfaces during defined human embryonic stem cell culture," Biointerphases, vol. 4, no. 4, pp. 69-79, 2009.

[37] M. McKenzie, D. Betts, A. Suh, K. Bui, L. D. Kim, and H. Cho, "Hydrogel-based drug delivery systems for poorly water-soluble drugs," Molecules, vol. 20, no. 11, pp. 2039720408, 2015.

[38] Y. Fang, B. Wang, Y. Zhao et al., "Collagen scaffold microenvironments modulate cell lineage commitment for differentiation of bone marrow cells into regulatory dendritic cells," Scientific Reports, vol. 7, article 42049, 2017.

[39] M. Caiazzo, Y. Okawa, A. Ranga, A. Piersigilli, Y. Tabata, and M. P. Lutolf, "Defined three-dimensional microenvironments boost induction of pluripotency," Nature Materials, vol. 15, no. 3, pp. 344-352, 2016.

[40] N. Brandenberg and M. P. Lutolf, "In situ patterning of microfluidic networks in 3D cell-laden hydrogels," Advanced Materials, vol. 28, no. 34, pp. 7450-7456, 2016.

[41] Y. Y. Lipsitz, N. E. Timmins, and P. W. Zandstra, "Quality cell therapy manufacturing by design," Nature Biotechnology, vol. 34, no. 4, pp. 393-400, 2016.
[42] B. van der Sanden, M. Dhobb, F. Berger, and D. Wion, "Optimizing stem cell culture," Journal of Cellular Biochemistry, vol. 111, no. 4, pp. 801-807, 2010.

[43] B. S. Mallon, K. Y. Park, K. G. Chen, R. S. Hamilton, and R. D. McKay, "Toward xeno-free culture of human embryonic stem cells," The International Journal of Biochemistry \& Cell Biology, vol. 38, no. 7, pp. 1063-1075, 2006.

[44] A. Schneider, D. Spitkovsky, P. Riess et al., "The good into the pot, the bad into the crop! - a new technology to free stem cells from feeder cells," PLoS One, vol. 3, no. 11, article e3788, 2008.

[45] T. Hartung, M. Balls, C. Bardouille et al., "Good cell culture practice. ECVAM good cell culture practice task force report 1," Alternatives to Laboratory Animals, vol. 30, pp. 407-414, 2002.

[46] F. Ng, S. Boucher, S. Koh et al., "PDGF, TGF- $\beta$, and FGF signaling is important for differentiation and growth of mesenchymal stem cells (MSCs): transcriptional profiling can identify markers and signaling pathways important in differentiation of MSCs into adipogenic, chondrogenic, and osteogenic lineages," Blood, vol. 112, no. 2, pp. 295-307, 2008.

[47] C. Lange, F. Cakiroglu, A. N. Spiess, H. Cappallo-Obermann, J. Dierlamm, and A. R. Zander, "Accelerated and safe expansion of human mesenchymal stromal cells in animal serum-free medium for transplantation and regenerative medicine," Journal of Cellular Physiology, vol. 213, no. 1, pp. 18-26, 2007.

[48] P. Goichberg, R. Kannappan, M. Cimini et al., “Age-associated defects in EphA2 signaling impair the migration of human cardiac progenitor cells," Circulation, vol. 128, no. 20, pp. 2211-2223, 2013.

[49] M. Csete, "Oxygen in the cultivation of stem cells," Annals of the New York Academy of Sciences, vol. 1049, pp. 1-8, 2005.

[50] D. Wion, T. Christen, E. L. Barbier, and J. A. Coles, " $\mathrm{PO}_{2}$ matters in stem cell culture," Cell Stem Cell, vol. 5, no. 3, pp. 242-243, 2009.

[51] J. A. King and W. M. Miller, "Bioreactor development for stem cell expansion and controlled differentiation," Current Opinion in Chemical Biology, vol. 11, no. 4, pp. 394-398, 2007.

[52] O. Karnieli, O. M. Friedner, J. G. Allickson et al., "A consensus introduction to serum replacements and serum-free media for cellular therapies," Cytotherapy, vol. 19, no. 2, pp. 155169, 2017.

[53] J. van der Valk, D. Brunner, K. De Smet et al., "Optimization of chemically defined cell culture media-replacing fetal bovine serum in mammalian in vitro methods," Toxicology In Vitro, vol. 24, pp. 1053-1063, 2010.

[54] S. Jung, A. Sen, L. Rosenberg, and L. A. Behie, "Identification of growth and attachment factors for the serum-free isolation and expansion of human mesenchymal stromal cells," Cytotherapy, vol. 12, pp. 637-657, 2010.

[55] C. E. Jochems, J. B. van der Valk, F. R. Stafleu, and V. Baumans, "The use of fetal bovine serum: ethical or scientific problem?," Alternatives to Laboratory Animals, vol. 30, pp. 219-227, 2002.

[56] G. Gstraunthaler, "Alternatives to the use of fetal bovine serum: serum-free cell culture,” ALTEX, vol. 20, pp. 275-281, 2003.

[57] D. A. Brindley, N. L. Davie, E. J. Culme-Seymour, C. Mason, D. W. Smith, and J. A. Rowley, "Peak serum: implications of serum supply for cell therapy manufacturing," Regenerative Medicine, vol. 7, pp. 7-13, 2012. 
[58] C. L. da Silva, Draft Guidance for Industry and Food and Drug Administration Staff Medical Devices Containing Materials Derived from Animal Sources (except for In Vitro Diagnostic Devices), Devices, Ed., U.S. Department of Health and Human Services, Food and Drug Administration, Center for Devices and Radiological Health, Transmissible Spongiform Encephalopathy Working Group, Office of Compliance, Office of Device Evaluation, Rockville, MD, USA, 2014, https://www .fda.gov/downloads/MedicalDevices/DeviceRegulationandGui dance/GuidanceDocuments/UCM381491.pdf.

[59] G. Gstraunthaler, T. Lindl, and J. van der Valk, "A plea to reduce or replace fetal bovine serum in cell culture media," Cytotechnology, vol. 65, pp. 791-793, 2013.

[60] J. van der Valk, D. Mellor, R. Brands et al., "The humane collection of fetal bovine serum and possibilities for serum-free cell and tissue culture," Toxicology In Vitro, vol. 18, no. 1, pp. 1-12, 2004.

[61] M. Mendicino, A. M. Bailey, K. Wonnacott, R. K. Puri, and S. R. Bauer, "MSC-based product characterization for clinical trials: an FDA perspective," Cell Stem Cell, vol. 14, pp. 141-145, 2014.

[62] ESAC, "ESAC statement on the use of FCS and other animalderived supplements," 2008: https://eurl-ecvam.jrc.ec.europa .eu/about-ecvam/archive-publications/publication/ESAC28_ statement_FCS_20080508.pdf.

[63] K. Gupta, A. Rispin, K. Stitzel, S. Coecke, and J. Harbell, "Ensuring quality of in vitro alternative test methods: issues and answers," Regulatory Toxicology and Pharmacology, vol. 43, no. 3, pp. 219-224, 2005.

[64] E. J. Culme-Seymour, N. L. Davie, D. A. Brindley, S. EdwardsParton, and C. Mason, "A decade of cell therapy clinical trials (2000-2010)," Regenerative Medicine, vol. 7, pp. 455-462, 2012.

[65] S. Jung, K. M. Panchalingam, L. Rosenberg, and L. A. Behie, "Ex vivo expansion of human mesenchymal stem cells in defined serum-free media," Stem Cells International, vol. 2012, Article ID 123030, 21 pages, 2012.

[66] C. Tekkatte, G. P. Gunasingh, K. M. Cherian, and K. Sankaranarayanan, "'Humanized" stem cell culture techniques: the animal serum controversy," Stem Cells International, vol. 2011, Article ID 504723, 2011.

[67] L. G. Chase, U. Lakshmipathy, L. A. Solchaga, M. S. Rao, and M. C. Vemuri, "A novel serum-free medium for the expansion of human mesenchymal stem cells," Stem Cell Research \& Therapy, vol. 1, no. 1, p. 8, 2010.

[68] N. Fekete, M. Gadelorge, D. Fürst et al., "Platelet lysate from whole blood-derived pooled platelet concentrates and apheresis-derived platelet concentrates for the isolation and expansion of human bone marrow mesenchymal stromal cells: production process, content and identification of active components," Cytotherapy, vol. 14, no. 5, pp. 540-554, 2012.

[69] N. Fekete, M. T. Rojewski, R. Lotfi, and H. Schrezenmeier, "Essential components for ex vivo proliferation of mesenchymal stromal cells," Tissue Engineering Part C, Methods, vol. 20, no. 2, pp. 129-139, 2014.

[70] V. T. Dos Santos, A. Mizukami, M. D. Orellana et al., "Characterization of human $\mathrm{AB}$ serum for mesenchymal stromal cell expansion," Transfusion Medicine and Hemotherapy, vol. 44, no. 1, pp. 11-21, 2017.

[71] P. Shetty, K. Bharucha, and V. Tanavde, "Human umbilical cord blood serum can replace fetal bovine serum in the culture of mesenchymal stem cells," Cell Biology International, vol. 31, no. 3, pp. 293-298, 2007.
[72] G. L. Francis, "Albumin and mammalian cell culture: implications for biotechnology applications," Cytotechnology, vol. 62, no. 1, pp. 1-16, 2010.

[73] K. Markó, M. Ligeti, G. Mezo et al., "A novel synthetic peptide polymer with cyclic RGD motifs supports serum-free attachment of anchorage-dependent cells," Bioconjugate Chemistry, vol. 19, no. 9, pp. 1757-1766, 2008.

[74] E. Giacomelli, M. Bellin, L. Sala et al., "Three-dimensional cardiac microtissues composed of cardiomyocytes and endothelial cells co-differentiated from human pluripotent stem cells," Development, vol. 144, no. 6, pp. 1008-1017, 2017.

[75] Y. Lin, K. L. Linask, B. Mallon et al., "Heparin promotes cardiac differentiation of human pluripotent stem cells in chemically defined albumin-free medium, enabling consistent manufacture of cardiomyocytes," Stem Cells Translational Medicine, vol. 6, no. 2, pp. 527-538, 2017.

[76] D. Yang, S. Chen, C. Gao et al., "Chemically defined serumfree conditions for cartilage regeneration from human embryonic stem cells," Life Sciences, vol. 164, pp. 9-14, 2016.

[77] V. Sovkova, K. Vocetkova, M. Rampichova et al., "Platelet lysate as a serum replacement for skin cell culture on biomimetic PCL nanofibers," Platelets, vol. 26, pp. 1-11, 2017.

[78] A. C. Paula, T. M. Martins, A. Zonari et al., "Human adipose tissue-derived stem cells cultured in xeno-free culture condition enhance c-MYC expression increasing proliferation but bypassing spontaneous cell transformation," Stem Cell Research \& Therapy, vol. 6, p. 76, 2015.

[79] N. C. Lobo, C. Gedye, A. J. Apostoli et al., "Efficient generation of patient-matched malignant and normal primary cell cultures from clear cell renal cell carcinoma patients: clinically relevant models for research and personalized medicine," BMC Cancer, vol. 16, p. 485, 2016.

[80] S. B. Poudel, G. Bhattarai, S. H. Kook et al., "Recombinant human IGF-1 produced by transgenic plant cell suspension culture enhances new bone formation in calvarial defects," Growth Hormone \& IGF Research, vol. 36, pp. 1-10, 2017.

[81] A. Fernandes-Platzgummer, J. G. Carmelo, C. L. da Silva, and J. M. Cabral, "Clinical-grade manufacturing of therapeutic human mesenchymal stem/stromal cells in microcarrierbased culture systems," Methods in Molecular Biology, vol. 1416, pp. 375-388, 2016.

[82] K. Turksen, "Adult stem cells and cardiac regeneration," Stem Cell Reviews, vol. 9, no. 5, pp. 537-540, 2013.

[83] G. Kania, K. R. Boheler, U. Landmesser, and W. Wojakowski, "Stem cells in heart failure," Stem Cells International, vol. 2011, Article ID 193918, 3 pages, 2011.

[84] A. Atmanli and I. J. Domian, "Recreating the cardiac microenvironment in pluripotent stem cell models of human physiology and disease," Trends in Cell Biology, vol. 27, no. 5, pp. 352-364, 2017.

[85] M. A. Laflamme and C. E. Murry, "Heart regeneration," Nature, vol. 473, pp. 326-335, 2011.

[86] M. A. Laflamme, S. Zbinden, S. E. Epstein, and C. E. Murry, "Cell-based therapy for myocardial ischemia and infarction: pathophysiological mechanisms," Annual Review of Pathology, vol. 2, pp. 307-339, 2007.

[87] T. J. Povsic and C. M. O'Connor, "Cell therapy for heart failure: the need for a new therapeutic strategy," Expert Review of Cardiovascular Therapy, vol. 8, no. 8, pp. 11071126, 2010. 
[88] R. S. Whelan, V. Kaplinskiy, and R. N. Kitsis, "Cell death in the pathogenesis of heart disease: mechanisms and significance," Annual Review of Physiology, vol. 72, pp. 19-44, 2010.

[89] V. F. Segers and R. T. Lee, "Stem-cell therapy for cardiac disease," Nature, vol. 451, no. 7181, pp. 937-942, 2008.

[90] R. Sanz-Ruiz, E. Gutiérrez Ibañes, A. V. Arranz, M. E. Fernández Santos, P. L. Fernández, and F. Fernández-Avilés, "Phases I-III clinical trials using adult stem cells," Stem Cells International, vol. 2010, Article ID 579142, 2010.

[91] A. Behfar, S. Yamada, R. Crespo-Diaz et al., "Guided cardiopoiesis enhances therapeutic benefit of bone marrow human mesenchymal stem cells in chronic myocardial infarction," Journal of the American College of Cardiology, vol. 56, no. 9, pp. 721-734, 2010.

[92] A. K. Patel, A. D. Celiz, D. Rajamohan et al., "A defined synthetic substrate for serum-free culture of human stem cell derived cardiomyocytes with improved functional maturity identified using combinatorial materials microarrays," Biomaterials, vol. 61, pp. 257-265, 2015.

[93] D. F. Torchiana, "(PEG hydrogels): polyethylene glycol based synthetic sealants: potential uses in cardiac surgery," Journal of Cardiac Surgery, vol. 18, no. 6, pp. 504-506, 2003.

[94] I. M. El-Sherbiny and M. H. Yacoub, "Hydrogel scaffolds for tissue engineering: progress and challenges," Global Cardiology Science and Practice, vol. 2013, no. 3, pp. 316-342, 2013.

[95] A. Hasan, A. Khattab, M. A. Islam et al., "Injectable hydrogels for cardiac tissue repair after myocardial infarction," Advanced Science (Weinheim), vol. 2, no. 11, article 1500122, 2015.

[96] K. M. Broughton and M. A. Sussman, "Myocardial regeneration for humans- modifying biology and manipulating evolution," Circulation Journal, vol. 81, no. 2, pp. 142-148, 2017. 

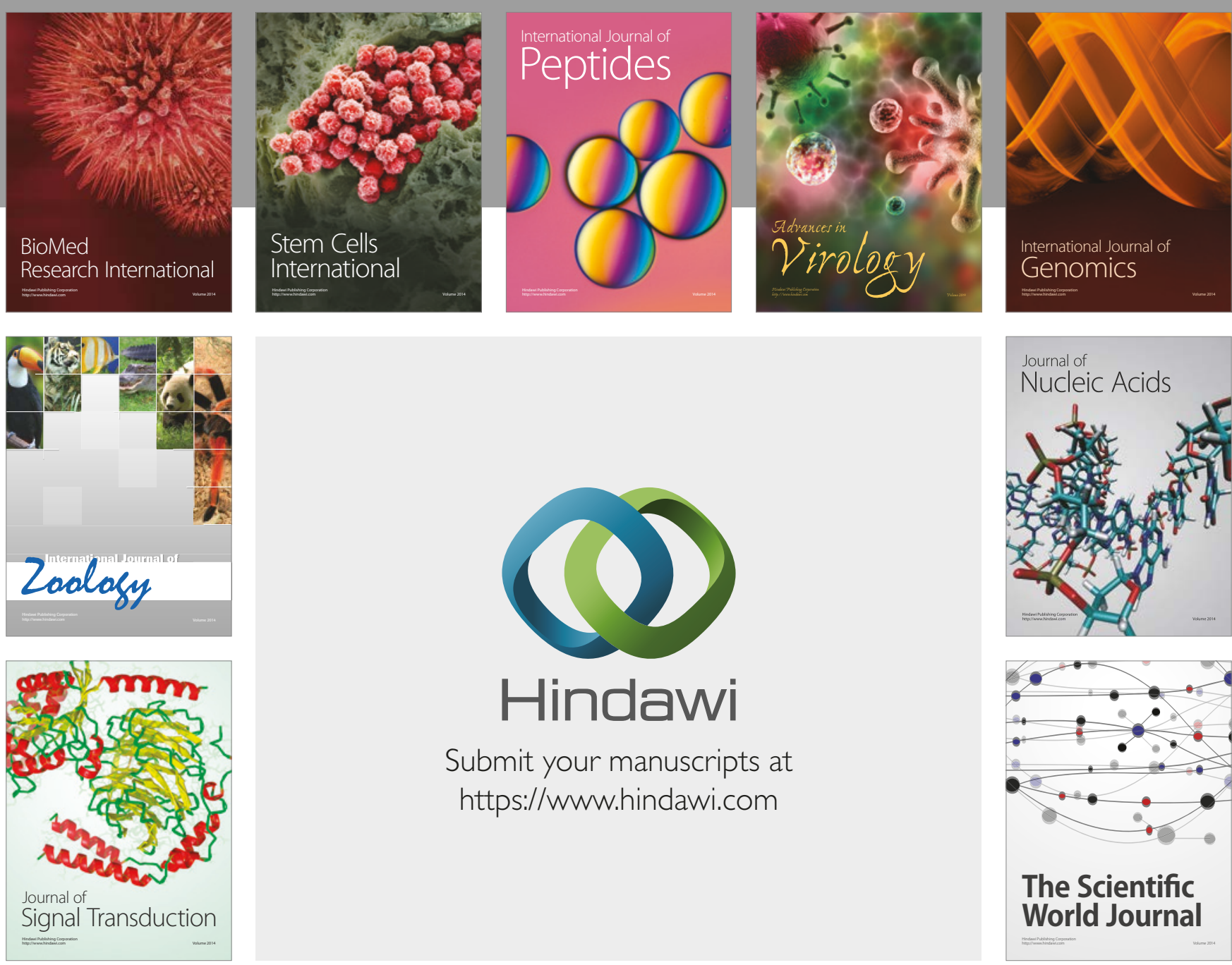

Submit your manuscripts at

https://www.hindawi.com
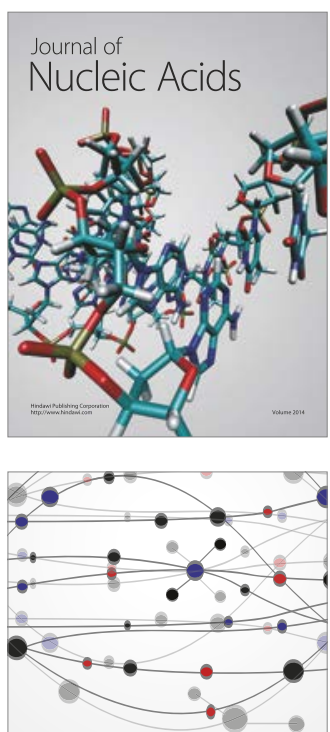

The Scientific World Journal

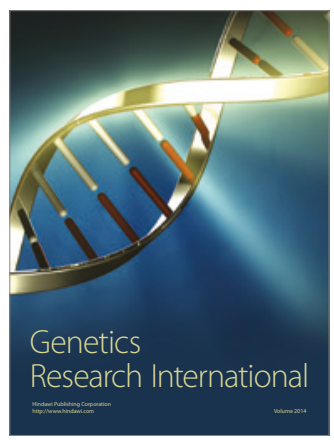

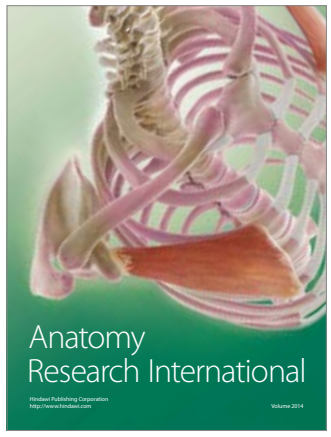

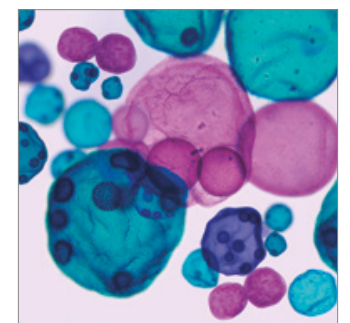

International Journal of Microbiology
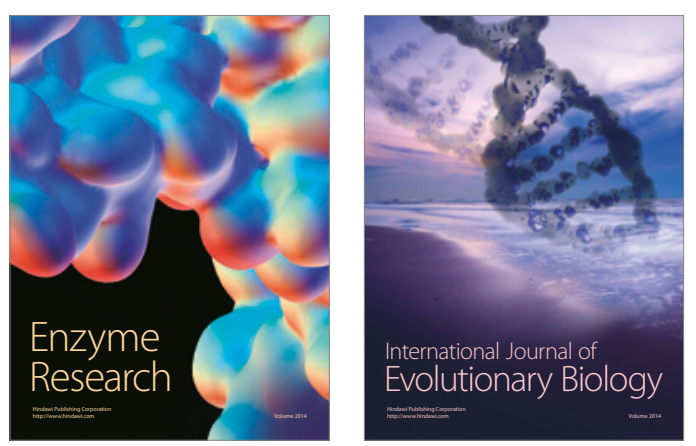
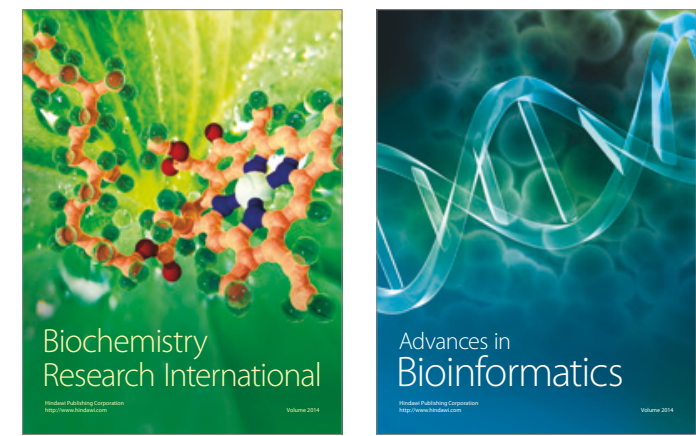

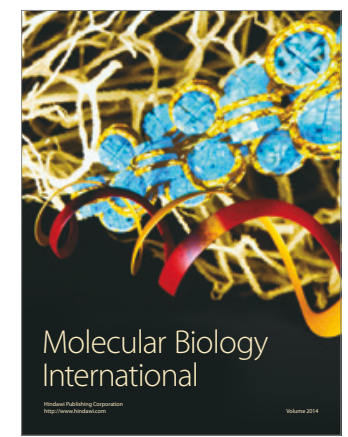

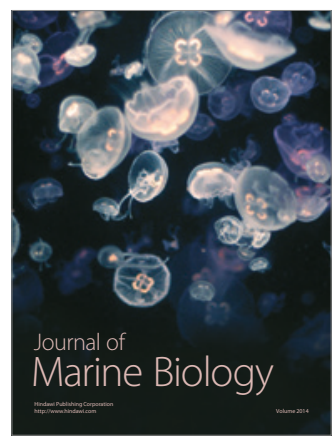

